\title{
Vena Cava
}

National Cancer Institute

\section{Source}

National Cancer Institute. Vena Cava. NCI Thesaurus. Code C12817.

A large vein which returns blood from the head, neck and extremities to the heart. 